\title{
Canada ranks No. 14 in world for retirees
}

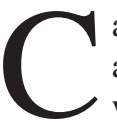

anada has dropped a notch in an international ranking of welfare in old age, but still places before France, the United Kingdom and the United States.

Canada maintained its overall score from last year in the 2014 Global Retirement Index, but slipped a rank, to 14th in the world for retiree welfare, just ahead of France.

Released Feb. 25 by Natixis Global Asset Management, the index ranks countries by relative performance across 20 indicators of health, material wellbeing, quality of life and finances in retirement, "as a guide to the changing decisions facing retirees as they focus on their needs and goals for the future."

The UK and US made the top 20 at numbers 18 and 19, respectively. Euro- pean nations, along with Australia and New Zealand, took the top 10 scores, with Switzerland, Norway and Austria ranking highest overall.

"Although these nations do have relatively high tax burdens, their citizens still benefit from some of the highest income levels per capita," according to the report. People in these countries also have outstanding universal health care systems and government policies geared toward "ensuring high standards with regards to the environment and overall well-being."

Retirees in Canada similarly benefit from a "top health-care system and other positive related outcomes, such as higher life expectancy," says Tracey Flaherty, senior vice president of government relations and retirement strategy at
Natixis. But the country's relatively high ranking is mostly attributable to the "overall health of the Canadian economy, which has weathered the financial crisis very well."'

Canada outperformed the average top 30 nations in quality of life and finances in retirement, but a closer look at the health subindex - which examines life expectancy and access to health care - paints a less flattering portrait. There, Canada squeezes into the top 30 at number 28, after Croatia and ahead of Estonia.

Part of the problem may be the way in which the index measures health, say Canadian experts on aging.

"It ignores the whole issue of how we as individuals would weigh these factors," says Dr. David Hogan, the

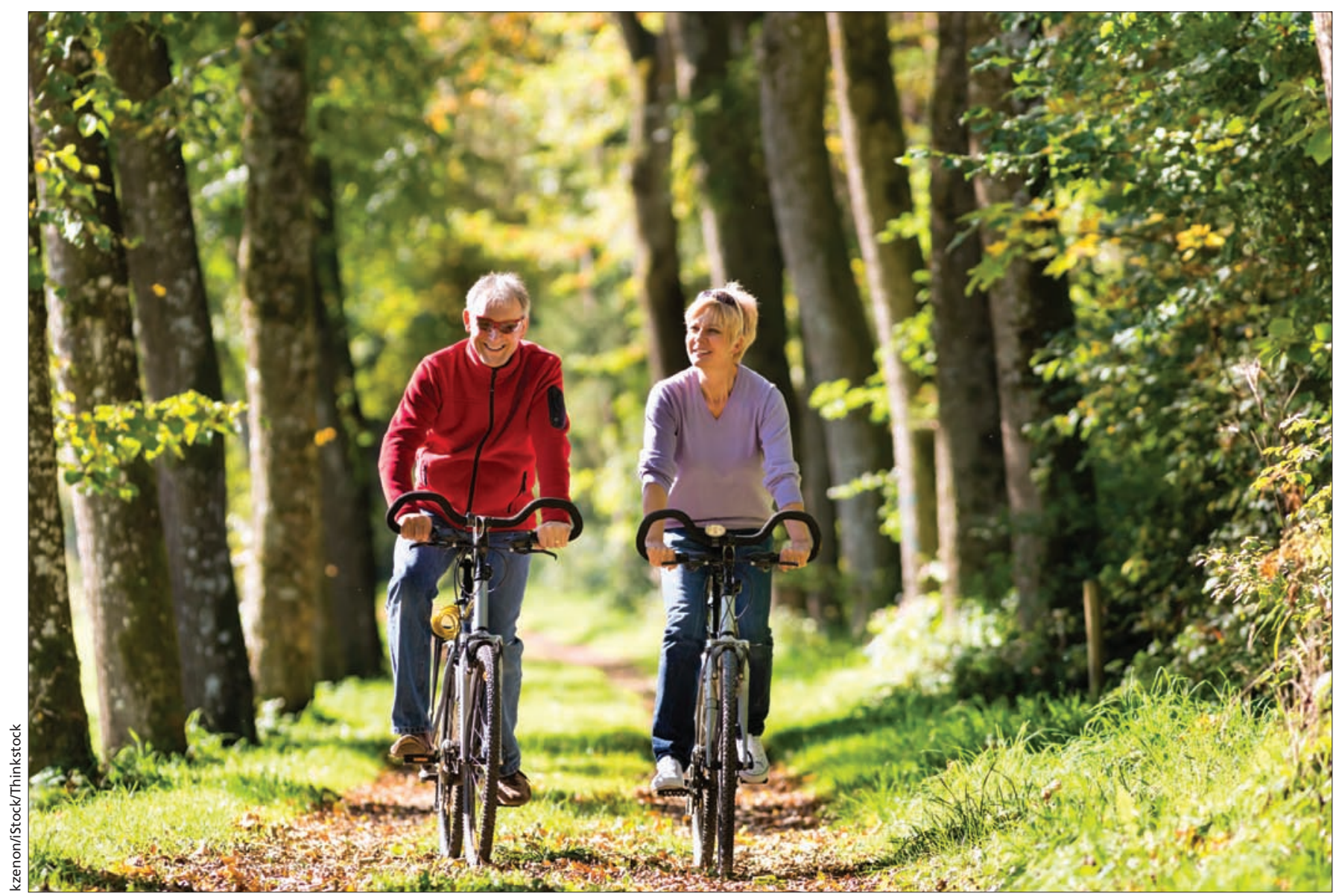

Canada ranks first in the world on "well-being" and "air pollution" indicators, according to the Global Retirement Index. 
Brenda Strafford Foundation chair in geriatric medicine at the University of Calgary in Alberta. "As I enter my later years, issues like proximity to those I know and love seem more important than factors like noninsured health expenditures."

Hogan also notes that the differences in scores between nations at the top of the index seem too "trivial" to be useful. "Is there really a difference between a score of $79 \%$ for Sweden (ranked 4th) and 78\% for Luxembourg (ranked 10th)?"
Verena Menec, the Canada research chair in healthy aging at the University of Manitoba in Winnipeg, takes issue with the report's assumption that bigger health bills and more hospital beds necessarily equate to a healthier population.

"What they're trying to get at is access to health services, but hypothetically if a country had a very healthy aging population, you presumably wouldn't need as many hospital beds," she says. "These are disease indicators, not health indicators."

That the index doesn't factor in ac- cess to home care is a further oversight, adds Menec.

However, some of these issues may be attributable to the inherent data restrictions of comparing 150 countries, including many developing nations, she says.

Meanwhile, Menec says the attempt to look at retirement in more than "strictly financial terms" is laudable. "Actually going broader is really positive." — Lauren Vogel, CMAJ

CMAJ 2014. DOI:10.1503/cmaj109-4754 